\title{
El suburbio moderno en pueblos de montaña: Cacheuta como caso de estudio (1900-1950) ${ }^{1}$
}

\author{
The Modern Suburb in Mountain Villages: \\ Cacheuta as a Case Study (1900-1950)
}

\author{
Pablo Bianchi. \\ Instituto de Ciencias Humanas, Sociales y Ambientales-Conicet \\ Universidad Nacional de Cuyo
}

DOI: https://doi.org/10.25032/crh.v6i11.13

Recibido: $10 / 08 / 2020$

Aceptado: 2/10/2020

Resumen. El artículo analiza el desarrollo del valle de Cacheuta (Mendoza) como enclave suburbano de montaña, al evidenciar un aumento en su oferta de actividades y servicios vinculados inicialmente al turismo medicinal, gracias a una serie de inversiones provenientes del sector público y privado. Cacheuta se convirtió en un testigo clave del proceso modernizador en los Andes Centrales de Argentina: las materialidades detectadas, como la estación del ferrocarril Trasandino y su barrio (1890) junto con el hotel termal (1913), evidenciaron un modo particular de apropiación del territorio, que sentó las bases para el poblamiento de la zona. El modelo narrativo histórico aporta las herramientas para el estudio de caso, que refleja un tipo singular de suburbio montañés, sustentado en la confianza en el progreso y las nuevas posibilidades ofrecidas por los avances tecnológicos.

Palabras clave: Suburbio moderno; Turismo; Poblado de montaña; Valle de Cacheuta

\footnotetext{
${ }^{1}$ Este trabajo surge del proyecto de investigación «Las dimensiones técnica y social que condujeron a Mendoza a la modernidad: obras y prácticas en los tramos superior y medio del río Mendoza (18901930)», financiado por la Dirección de Investigaciones de la Universidad de Mendoza-DIUM, Convocatoria 2017-2019, cuyos primeros resultados fueron expuestos en los artículos «La modernidad en Mendoza (1890-1930): el enclave Cacheuta como testimonio de montaña» (2019) y «Los poblados históricos del área de frontera en la naciente del río Mendoza: un testimonio de la modernidad finisecular (1890-1950)» (2020).
} 
Abstract. The article analyzes the development of the Cacheuta Valley (Mendoza), as a suburban mountain settlement, which shows an increase in its offer of activities and services initially linked to health tourism, due to a series of investments from private and public agents. Cacheuta became a key witness of the modernization process in the Central Andes of Argentina: the detected constructions, such as the Trasandino Railway Station and its neighborhood (1890), along with the thermal spring Hotel (1913), showed a particular way of appropriating the territory that laid the foundations for the settlement of the area. The Historical Narrative Model provides tools for the case study, which reflects a unique type of mountain suburb, based on confidence in progress and the new possibilities offered by technological advances.

Keywords: Modern Suburb; Tourism; Mountain Village; Cacheuta Valley

\section{Introducción}

La zona de los Andes Centrales argentinos desplegó su potencial turístico a fines del siglo XIX: la construcción de los primeros hoteles de montaña, estimulada por la acción del ferrocarril en la cordillera, inauguró actividades turísticas precursoras vinculadas al termalismo. ${ }^{2}$ A ellas se sumaron, posteriormente, «la práctica de deportes invernales, cabalgatas, senderismo y andinismo» (Lacoste 217a).

La línea férrea fue el instrumento que ayudó a jalonar los pueblos, acodados entre el serpenteo del río Mendoza y las cumbres montañosas. Paralelamente, se inició el poblamiento en torno a las distintas estaciones ferroviarias que, convertidas rápidamente en el centro de acción de los asentamientos, modificaron la configuración demográfica del territorio y contribuyeron a consolidar un vasto y prolongado proceso de poblamiento, que había comenzado con la fundación de postas a lo largo del Camino Real, que comunicaba Buenos Aires con Santiago. En este sentido, las Casuchas del Rey (1765c.), que prestaban albergue a lo largo del tramo cordillerano de este camino dejaron de cumplir, con la llegada del tren, su función primaria de intercambio y descanso (caso de la posta de Villavicencio),

\footnotetext{
${ }_{2} \mathrm{Al}$ respecto, se sugiere revisar La conquista de las vacaciones de Elisa Pastoriza y El Ferrocarril Trasandino y el desarrollo de los Andes centrales argentino-chilenos (1872-2013) de Pablo Lacoste, que abordan la emergencia de las primeras estaciones termales de la cordillera argentina.
} 
fueron adaptándose a nuevas condiciones (postas de Uspallata, Puente del Inca y Las Cuevas), o bien desaparecieron definitivamente (Pastor y Raffa 2013).

En este contexto, el valle de Cacheuta se convirtió en un testigo clave del proceso modernizador en la montaña: desde la llegada del ferrocarril Trasandino (FCT) en 1890 y durante buena parte del siglo $\mathrm{Xx}$, el valle fue objeto constante de inversiones que permitieron incrementar su oferta de actividades y de servicios vinculados al turismo medicinal.

Las primeras instalaciones de infraestructuras, materializadas como estaciones intermedias del ferrocarril; generaron conjuntos de viviendas, albergues y algunos comercios. Estos componentes, reunidos en frágiles asentamientos, permitían un incipiente intercambio de mercancías a la vez que facilitaban el transporte. La construcción de semejante empresa demandó una importante inversión financiera inicial, tanto del Estado como sostenida por capitales británicos, 3 además de requerir una considerable cantidad de mano de obra que se albergó en campamentos, marcando el inicio del poblamiento permanente en la zona. En el caso particular de Cacheuta, esta situación se vio favorecida por la traza del camino vehicular en la década de 1920 que, si bien no ofrecía una competencia significativa respecto de las posibilidades de carga y transporte de pasajeros del FCT, abría una vía alternativa de acceso a las villas de montaña.

En tal sentido, el problema planteado en este artículo indaga sobre el desarrollo de un tipo de suburbio montañés en el marco de la modernización, en que las arquitecturas utilitarias necesarias para el funcionamiento del ferrocarril, junto con las surgidas del naciente turismo en el sector; manifiestan un esquema de agrupamiento de altísima singularidad, puesto que encarnan la construcción simbólica de la modernidad en un contexto adverso. Esto requirió de un cambio de mentalidad respecto de la montaña, valorada como espacio «vacío» (Corbin 1993) y asociada históricamente a la idea de lo exótico e inhóspito, es decir, incapaz de sostener población permanente. Advertimos que la forma de agrupamiento fundacional aludida se vincula íntimamente con líneas estructurantes naturales,

\footnotetext{
3 La Ley 583 sancionada por el Congreso de la Nación en 1872 definió costos y fijó las obligaciones del Estado y de las empresas concesionarias privadas para la construcción del trasandino. El contrato con la empresa de los hermanos Clark, que resultó adjudicataria de la obra, se firmó en el marco de esta ley. Pablo Lacoste. El Ferrocarril Trasandino y el desarrollo de los Andes Centrales argentinochilenos (1872-2013). Santiago de Chile: IDEA, 2013.
} 
como el cauce del río Mendoza; o bien generadas por la antropización gradual del sector, como la línea férrea en un primer momento y posteriormente la trama vial.

En términos de la evolución de las prácticas de ocio, la llegada del ferrocarril provocó un fenómeno que Boyer (2002) denomina «revolución turística».4 El tren acorta distancias, permite un intercambio fluido de personas y mercancías y los desplazamientos adquieren carácter estacional. Para el caso del balneario termal de Cacheuta, se verificó en ese momento histórico un evento de «invención y difusión» que, en palabras del autor, permite comprender el proceso de emergencia del sitio y de consolidación por la afluencia constante de visitantes ilustres o de clases acomodadas. 5

Así, se plantea como objetivo principal de este trabajo explorar el desarrollo del suburbio de montaña en el área bajo estudio, ${ }^{6}$ en el escenario de surgimiento del ferrocarril, signado por la confianza en el progreso y el uso de nuevas tecnologías y materiales. En segundo término, busca indagar en las transformaciones que, en su condición periférica, experimentó el sector analizado, tanto desde la organización espacial de las actividades como desde su desarrollo material en clave arquitectónica, durante la primera mitad del siglo $\mathrm{xx}$, como producto de políticas públicas y acciones privadas orientadas al desarrollo del comercio, del transporte y del turismo en la zona, a fin de identificar sus dinámicas de cambio y las prácticas asociadas.

Para cumplir con tales objetivos, se parte de dos supuestos: el primero postula que la acción del ferrocarril y la presencia del hotel termal constituyeron un binomio decisivo a la hora de viabilizar el asentamiento humano permanente en la zona bajo estudio. Si bien existen indicios de presencia humana en el valle desde tiempos prehispánicos (Michieli 1994), es solo a partir de la llegada del ferrocarril que se detecta un avance en el proceso de poblamiento histórico que irá evolucionando a lo largo del siglo Xx. El segundo supuesto sostiene que la modernización tuvo efectos particulares en los poblados de la montaña, al establecer formas de apropiación del territorio adaptadas a las singulares condiciones topográficas del terreno, con el

\footnotetext{
4 Refiere a otros descubrimientos hechos por los británicos en relación con «prácticas de ociosidad, migraciones codificadas y lugares de excepción», en analogía a las grandes revoluciones que se dieron en Gran Bretaña, de manera simultánea. Marc Boyer, «El turismo en Europa, de la edad moderna al siglo XX», Historia Contemporánea, 25 (2002): 13-31.

$5 \mathrm{El}$ autor enumera un último estadio: la «búsqueda de nuevos destinos cuando el anterior deja de revestir un carácter específico de distinción», que, para el caso del balneario de Cacheuta, no llegó a concretarse dado que su consolidación se vio truncada por un aluvión en 1934.

${ }^{6}$ Espacio acotado entre el km 37 y el km 40 de la ruta del FCT, que no opera en la actualidad.
} 
desarrollo de los trazados, tanto ferroviario como carretero, como ejes ordenadores de sus materialidades.

Ahora bien ¿́cuál es la conceptualización de «modernidad» que sigue este trabajo? Se toma la definición de Berman (1988) vinculada a los orígenes del capitalismo, donde la tecnología cobra un papel relevante, junto con la distinción entre modernización y modernidad propias del siglo xx. La modernización refiere a un entramado «complejo de estructuras y procesos materiales (políticos, económicos y sociales)», mientras que la modernidad encarna «un espíritu puro que evoluciona de acuerdo con sus imperativos artísticos e intelectuales autónomos».7 Respecto del concepto de suburbio, adherimos a la definición de Solà-Morales (1997), quien identifica un tipo de organización del espacio denominado «parcelación industrial», a partir de la apertura de vías que «urbanizan» (en el sentido de poner en valor y dar accesibilidad) nuevo suelo. Este tipo de organización sigue unas operaciones materiales intrínsecas al crecimiento suburbano, con un orden preestablecido de ocurrencia: en primer lugar la urbanización, en segundo término la parcelación y finalmente la edificación. ${ }^{8}$

Desde la disciplina histórica arquitectónica este trabajo adhiere a la propuesta teórica de Waisman (1993 y 1972), para el estudio de arquitecturas «modestas». Respecto del concepto de tipo, Waisman (1993) y Trachana (2011) le asignan el papel de instrumento, al definir una red de relaciones topológicas que dan por resultado una determinada organización volumétrico-espacial y una determinada relación con el entorno. La investigación constituye un abordaje de carácter descriptivo, explicativo y no experimental, que recurre al modelo narrativo histórico propuesto por Sautu et al. (2005).

Las fuentes de las que se nutre la investigación incluyen artículos de promoción turística (Revista Mensual B.A.P., Revista Mensual Ilustrada Luz y Fuerza), postales, fotografías, cartografía histórica y labores de gobierno; examinadas bajo las técnicas del análisis fotográfico (Barthes 1992) y el análisis del discurso (Van

\footnotetext{
7 Marshall Berman, Todo lo sólido se desvanece en el aire. La experiencia de la modernidad. (Madrid: Siglo Veintiuno Editores, 1988), 127.

$8 \mathrm{El}$ autor entiende a la urbanización, como la «operación de construcción de los elementos físicos colectivos», a la parcelación como la «transformación del suelo rústico en urbano, o la atribución de un uso urbano a un suelo» y la edificación refiere a la construcción de las obras de arquitectura. Manuel de Solà-Morales Rubió, Las formas de crecimiento urbano. (Barcelona: Edicions UPC, 1997), 78.
} 
Dijk 2016), junto a la observación directa (Marradi et al. 2007) de los componentes que subsisten actualmente del caso bajo estudio y su entorno.

La investigación es tributaria de los estudios de Pastoriza y Torre (2019), Pastoriza (2011), Bruno (2009) y Booth et al. (2002). ${ }^{9}$ Gutiérrez (1983) explora los pueblos ferroviarios surgidos en el siglo XIX, aunque no profundiza en los modos de ocupación del territorio de montaña, si bien reconoce que el ferrocarril «contribuyó a desarrollar las potencialidades tanto de las terminales como de los puntos intermedios de los trazados» (1983 503).

En el ámbito europeo, los trabajos de Butler (1985) y Larrinaga Rodríguez (2015 y 2002) constituyen aportes señeros en nuestra misma línea de investigación.10 En el contexto local, este trabajo sigue a Lacoste (2013 2004 y 1998), como antecedente directo de abordaje, puesto que indaga en «la invención de la montaña como espacio social». Finalmente adherimos a De Fusco (1992), en el modo de estudiar las características arquitectónicas propias de la industrialización, centrado en el caso inglés como foco difusor de estéticas e ideologías.

La primera parte del artículo expone los procesos de fundación y crecimiento suburbano en el valle de Cacheuta, como consecuencia de la modernización imperante, tanto para el poblado de la estación como para el hotel termal. Seguidamente, se introducen las alteraciones producidas en el enclave a partir del trazado de la autovía y los nuevos actores presentes, que presionan sobre el enclave según sus particulares intereses: el Estado con el fomento del turismo y la Compañía de Luz y Fuerza con la implantación de una central hidroeléctrica y su barrio. Para concluir, se contrastan las dinámicas de cambio vinculadas a los procesos observados; junto al modo en que sus materialidades denotan la acción modernizadora del ferrocarril en un enclave de montaña.

\section{Cacheuta como suburbio de montaña: rieles y ocio}

\footnotetext{
9 A diferencia de este trabajo, que aborda la modernización en un suburbio montañés, sus aportaciones indagan en las prácticas sociales y en los modelos arquitectónico-urbanos imitados del contexto europeo, junto con intervenciones estatales, que sentaron las bases para la conformación de balnearios de playa como destinos turísticos.

${ }^{10}$ Larrinaga aborda el desarrollo del turismo en España en general y del termalismo en el País Vasco en particular, mientras que Butler indaga en la evolución del turismo en las Highlands escocesas, en el siglo XVIII y XIX, cuandoidentifica los cambios sociales, económicos y tecnológicos con especial interés en las infraestructuras, el transporte y el uso de la tierra.
} 
El cambio de paradigma provocado por la industrialización implicó para Mendoza la incorporación de nuevos espacios geográficos al esquema productivo agrario predominante. Así, el proceso de transformación económica que experimentaba la provincia se orientó hacia una «vitivinicultura moderna» y al aumento poblacional, que garantizara la extensión de la agricultura y el mejoramiento de las artes e industrias, sustentado en la inmigración que «sentaba las bases de una política de colonización y ocupación efectiva del suelo» (Cueto et al. 1991).

Además del termalismo, que se desarrolló en paralelo con el tendido de la traza ferroviaria, la modernización en el valle de Cacheuta quedó evidenciada en los saberes que aportaban los ingenieros y técnicos llegados de países europeos, pero sobre todo en una renovada actitud del hombre respecto del espacio «vacío» de la montaña (Corbin 1993), como resultado del positivismo vigente que postulaba una confianza sostenida en la idea de eterno progreso sumada al ímpetu de dominio de la naturaleza. Esta visión, heredada del siglo XVIII, pregonaba puntualmente para las actividades referidas al ocio «la apreciación de los paisajes según las convenciones de lo «pintoresco» o, más tarde, de lo «sublime»»; y provocó, en la centuria siguiente, una búsqueda de «experiencias estéticas y espirituales de encuentro con la naturaleza...».11

El proceso de europeización fue un hecho incuestionable a partir de la presencia masiva de extranjeros que aportaron sus conocimientos, costumbres, formas de pensar y capacidad en el trabajo. Asimismo, se desarrollaron mundos culturales paralelos: el de la clase alta que vivía la belle èpoque, al nivel de la aristocracia europea, refinada y culta, que buscaba desarrollar sus espacios de ocio; la naciente clase media, de costumbres austeras, que construía su futuro y la clase del inmigrante, responsable de desarrollar la meritocracia por su voluntad de trabajo.

En este contexto, la labor de visionarios que aportaron ideas, capital y mano de obra a los territorios del valle de Cacheuta, transformó el escenario primitivamente indómito de la montaña en un reducto de generación de riqueza. Las perforaciones en busca de petróleo en el cerro Cacheuta, los emprendimientos de aprovechamiento del río para la producción de energía hidroeléctrica y el desarrollo del turismo medicinal,

\footnotetext{
11 John Walton, «Aproximación a la historia del turismo en el Reino Unido, siglos XVIII-XX», Historia Contemporánea, 25 (2002): 65-82.
} 
actividades involucradas en mayor o menor medida con el ferrocarril, cambiaron la fisonomía del lugar, haciéndolo apto para el asentamiento humano permanente y apetecible para el establecimiento progresivo de inversiones..$^{12}$

\subsection{El poblado de Cacheuta}

En 1887 el gobierno nacional comenzó la construcción del FCT, con el objeto de unir los puertos de Buenos Aires y Valparaíso. La dirección de las obras se concesionó a la empresa de los hermanos Juan y Mateo Clark, que impulsaron la alternativa de la ruta por Las Cuevas, ${ }^{13}$ ante otras propuestas que sugerían una traza por la zona sur de Mendoza. En carácter de consultora tuvo participación desde Londres la empresa de los ingenieros Livesey, Son \& Henderson, con amplia experiencia en la construcción de puentes ferroviarios y responsable de numerosas obras en Sudamérica, Oceanía y África.

La línea enlazaba las localidades de Mendoza y Las Cuevas como punto más occidental del trazado; pasando por Cacheuta, Potrerillos, Uspallata y Puente del Inca. La obra demoró casi 20 años en concretarse, debido a la «magnitud y el carácter binacional de la obra»,14 la inestabilidad política imperante y las dificultades técnicas. ${ }^{15}$ En 1910 y con la finalización del túnel de la Cumbre, se libró definitivamente al servicio el FCT.

12 En 1887 el ingeniero Carlos Fader (un inmigrante alemán), representante de la Compañía Mendocina de Petróleo, informó al gobierno de la Provincia sobre veinte perforaciones realizadas en el cerro Cacheuta, que entre los $80 \mathrm{~m}$ y $290 \mathrm{~m}$ de profundidad, permitieron extraer petróleo en abundancia y de manera continua. Los auspiciosos resultados motivaron a Fader a presentar una serie de mejoras, entre ellas, la instalación de una usina a gas de petróleo. Fracasado el acuerdo con el FCT para el transporte del crudo, se construyó un tendido de $34.000 \mathrm{~m}$ de cañería, de 3 pulgadas y media, para conducir el fluido hasta Godoy Cruz, empresa que se conoce como el «primer oleoducto de Sudamérica» (Cien años de vida mendocina. Centenario diario «Los Andes». 1882- 1982. [Mendoza] Los Andes, 1982, p. 22). Otras inversiones destacadas de la época fueron la instalación de una usina hidroeléctrica (1899-1913), también por iniciativa de Carlos Fader, y la finalización y puesta en servicio de la usina de Cacheuta (1926) por la Empresa de Luz y Fuerza.

13 Según apunta Lacoste (a), esta variante del Trasandino buscaba vincular ramales existentes, evitando la superposición de rieles, tanto del lado argentino como chileno, para abaratar costos. Así, se vincularon el ferrocarril Gran Oeste Argentino y el Trasandino con una estación de trasbordo en Mendoza. Los distintos tramos y sus años de construcción, en el trayecto entre Buenos Aires y Salto del Soldado comprendieron la sección Buenos Aires-Mercedes entre 1855 y 1865; Villa Mercedes-San Juan entre 1880 y 1885; Mercedes-Villa Mercedes entre 1882 y 1886; Mendoza-Punta de Vacas entre 1887 y 1893 y finalmente la sección en Chile entre las estaciones Los Andes-Salto del Soldado entre 18891893.

14 Lacoste, El Ferrocarril Trasandino 110.

15 La crisis provocada por la revolución de 1890 obligó a renunciar al presidente Juárez Celman, provocando una retracción de las inversiones a largo plazo. La falta de financiamiento arruinó a los hermanos Clark, quienes se retiraron del proyecto con la consiguiente paralización de los trabajos. Sumado a ello, las dificultades entre Argentina y Chile para resolver cuestiones limítrofes demoraron 
La estación Cacheuta, inmersa en las primeras estribaciones montañosas luego de superar las serranías de Blanco Encalada, constituyó el centro neurálgico del primitivo poblado: el edificio de la estación, un tanque de agua elevado, un pequeño grupo de viviendas y un galpón de depósito fundaron los primeros testimonios arquitectónicos permanentes en la avanzada sobre el territorio (Figura 1).

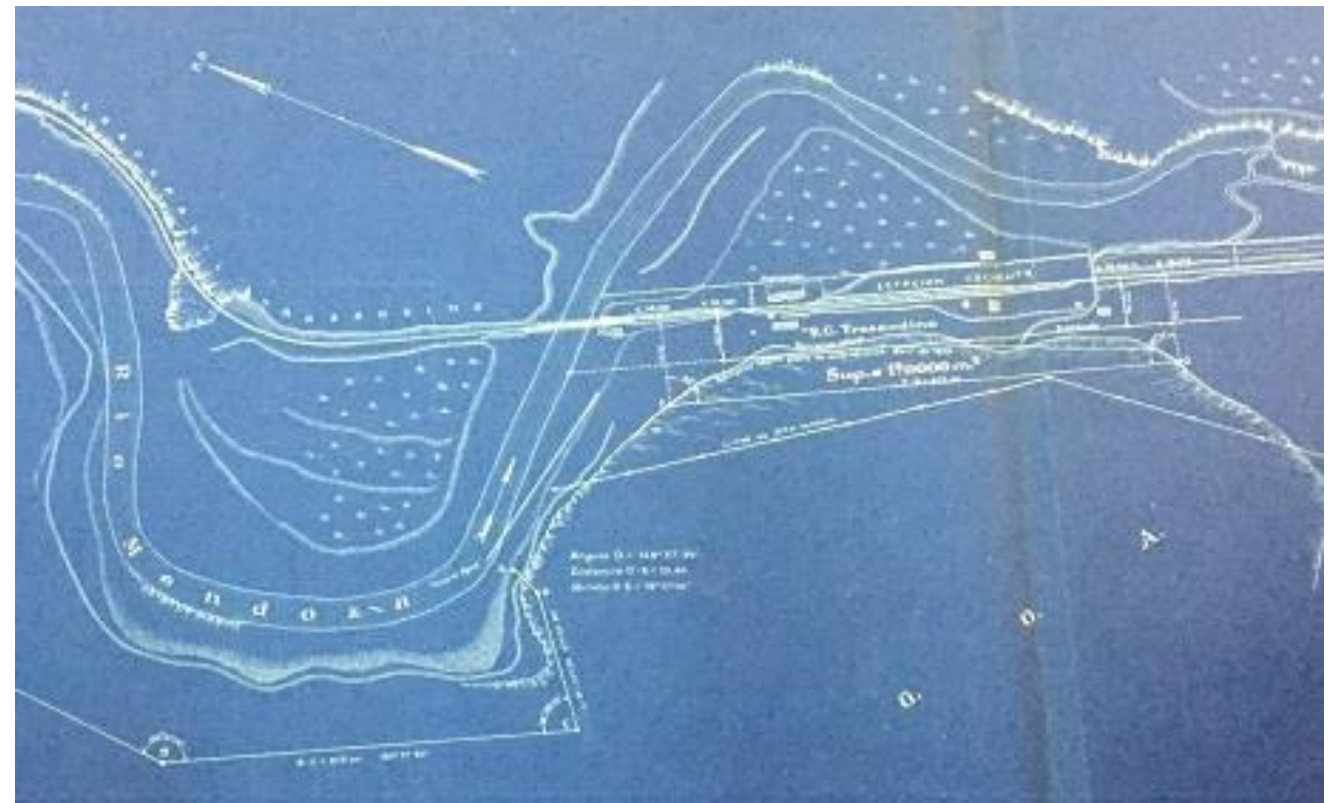

Figura 1: Poblado de Cacheuta, (1910). Archivo del Ente Provincial Regulador Eléctrico (EPRE). «Plano de los terrenos vendidos por las compañías de Ferrocarriles Gran Oeste Argentino y Buenos Aires al Pacífico a la Empresa de Luz y Fuerza, en Cacheuta, Depto. de Luján» (fragmento). Copia realizada por Enrique del Castillo en 1927.

En este sector, el río presentaba un recorrido tortuoso en forma de S, que delimitaba dos porciones de terreno: la sección norte albergó el trazado sobre una elevación natural, la parte sur sobre una amplia terraza junto a la ribera del río, de manera que el esquema, de carácter espontáneo, quedó estructurado a lo largo de la vía férrea y rodeado de un paisaje montañés de singular belleza. ${ }^{16}$ La construcción del puente ferroviario sobre el río Mendoza permitió vincular el cerro de mayor altura,

aún más las obras hasta la firma, en 1902, del acuerdo de paz conocido como «Pactos de Mayo». Lacoste, El Ferrocarril Trasandino 113.

16 «El enclave Cacheuta se ubica en un sector montañoso de la precordillera de los Andes, con alturas intermedias de 1150 y 1430 msnm [...] Este tramo escarpado refiere al lecho natural del río Mendoza, que discurre en sentido sureste en una quebrada entre montañas con un cauce estrecho y abrupto. El lecho del río, de marcada pendiente, es peñascoso y las paredes que lo definen forman una unidad morfológica única. Presenta una marcada variabilidad térmica, con vientos frescos y régimen de precipitaciones estivales. Su flora es xerófila, manifiesta en vegetación achaparrada, de gruesos troncos adaptadas al calor y al medio seco». Pablo Bianchi y Ana María Villalobos, "La modernidad en Mendoza (1890-1930): el enclave Cacheuta como testimonio de montaña», Anales de Investigación en Arquitectura, 9 (2019): 69-88. 
ubicado al norte, con la estación y las viviendas dispuestas en la margen sur del río, a lo largo de la vía del tren.

De este modo, se materializó un espacio moderno propio de la infraestructura ferroviaria, que asumió rápidamente las funciones de aglutinador de las actividades presentes hasta el momento, como vía de conexión entre las partes del poblado y espacio público de intercambio social (Figura 2).

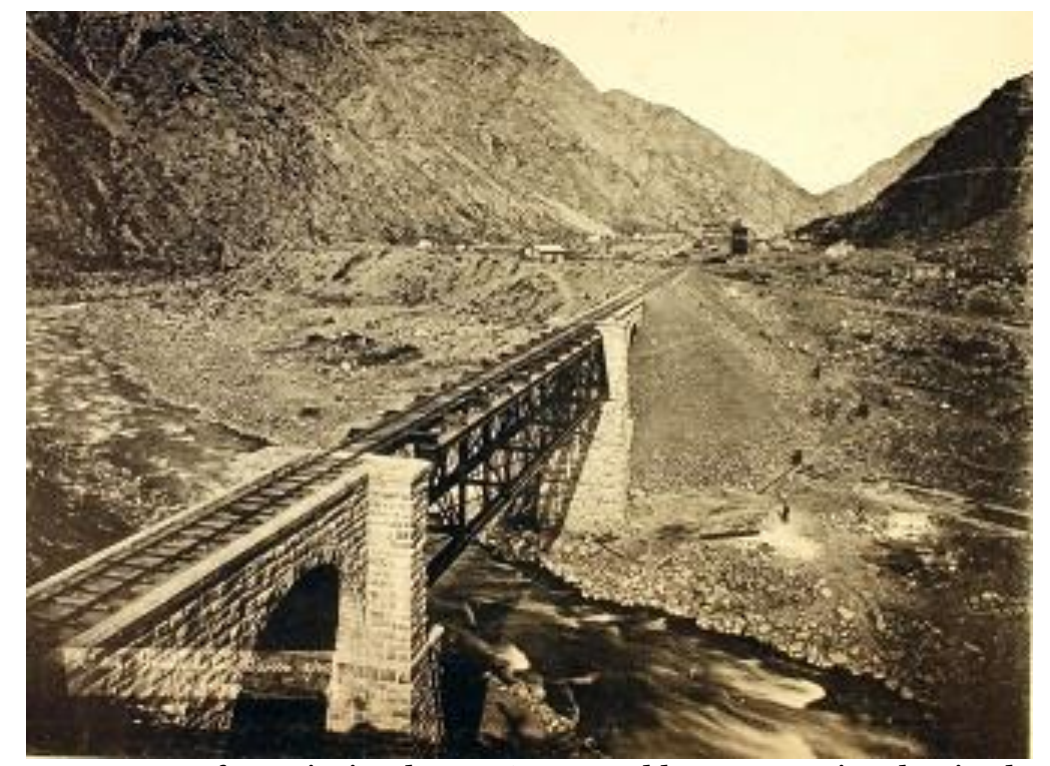

Figura 2: Puente ferroviario «los Baños» en el km 38,7 y vista hacia el sur del pueblo de Cacheuta (1907). Fuente: Colección Alex Gulliver, Archivo Nacional de Chile.

Del análisis de fotografía histórica se desprende que el barrio de operarios a cargo de los trabajos (del que no quedan vestigios materiales), se ubicaba en el cerro más alto, posiblemente por el dominio visual de toda la zona. El establecimiento en ese lugar requirió tareas de desmonte de la cima y de la ladera oeste, lo que permitió en un primer momento instalar el campamento y acopiar materiales y enseres sobre terrazas escalonadas. Las características topográficas, las condiciones extremas de trabajo y las dificultades propias de la obra significaban un peligro latente para la vida de los involucrados, por lo que algunas sepulturas aisladas se convirtieron con el correr del tiempo en el cementerio del lugar, ubicado en la misma ladera.

Hacia 1917 se construyó en ese mismo promontorio y con carácter permanente, un conjunto constituido por una escuela (luego Escuela Nacional n. ${ }^{\circ}$ 54), chalet para el director y cuatro viviendas apareadas, resultado de una donación 
particular. ${ }^{17}$ Esta donación buscaba facilitar un espacio adecuado para la formación de niños de la zona, que inicialmente debían desplazarse $28 \mathrm{~km}$ aguas abajo, hasta la villa cabecera de Luján de Cuyo, para acceder a la escolarización primaria. Las viviendas y la escuela fueron resueltas en tecnología de piedra labrada, extraída del lugar, con cubiertas de chapa con pendientes a dos y cuatro aguas, y aberturas con dinteles pétreos en arcos de medio punto rebajados.

La escuela presentaba un volumen unitario, con planta en forma de V. En el vértice se ubicaba el acceso principal, orientado al sur y abierto hacia un patio con un mástil y una plaza de ceremonias, dominada por una ermita con una imagen religiosa. En los brazos y hacia el norte se abría una galería que comunicaba en un extremo el salón de las niñas, con su correspondiente sanitario y hacia el otro extremo el de los niños. Entre el vestíbulo de acceso ubicado en el eje de la composición y los dos salones de clases, se ubicaban la dirección y la portería, en locales de menor superficie que articulaban el partido, resuelto con absoluta simetría. ${ }^{18}$ Las viviendas se resolvieron hacia el este de la escuela, en una planta rectangular, con un partido espejado por el cual los accesos se disponían en los vértices extremos del rectángulo. Una extracción al volumen en cada extremo generaba un hall de acceso semicubierto para cada vivienda. El chalet se ubicó alineado a las viviendas en el extremo sur del planteo y respondiendo a la misma tipología y materialidad.

La vía férrea permitió abrir camino en el territorio, y en mayor o menor medida esto se tradujo en la instalación de equipamientos, como la escuela descripta. El desarrollo turístico del valle contó también con una oferta de menor categoría que el famoso hotel termal: la posada Quirós, un albergue modesto ubicado en un cerro enfrentado a la escuela y su barrio, al otro lado de la vía. Los anuncios publicitarios relevados dan cuenta de su existencia desde fines de la década de 1920.

El conjunto contaba con tres edificios ordenados a uno y otro lado de un eje perpendicular a la línea ferroviaria, y dos construcciones más hacia el este, dispuestas

\footnotetext{
17 Parte de la donación para la construcción de la escuela fue concretada por Victoria Aguirre Anchorena (1858-1927), que había visitado las termas y conocía muy bien el lugar, según una de las fuentes relevadas. Aguirre «integraba una Sociedad de Beneficencia, con la cual muchas escuelas, asilos, hospitales, instituciones religiosas, culturales, científicas y deportivas contaron con su apoyo desinteresado». El Territorio diario on line [Misiones], dic. 7, 2018.

${ }^{18}$ Esta información se pudo constatar en el plano «Reparaciones y obras sanitarias. Planta y corte $\mathrm{AB}$ », año 1931, del Ministerio de Obras Públicas-Dirección General de Vías y Comunicaciones y Arquitectura. Archivo CEDIAP-AABE.
} 
en forma de L, de manera que todo el complejo era visible desde el acantilado en la ribera opuesta, donde se encontraba la estación y su barrio. La fotografía histórica permite comprobar que, al igual que en el caso de la escuela, la ladera del cerro se desmontó en forma aterrazada para evitar desprendimientos; luego fue reforzada con pircas en piedra labrada y trabada sin mortero, dando una imagen homogénea a partir de la mímesis entre las construcciones y el relieve del sector (Figura 3).

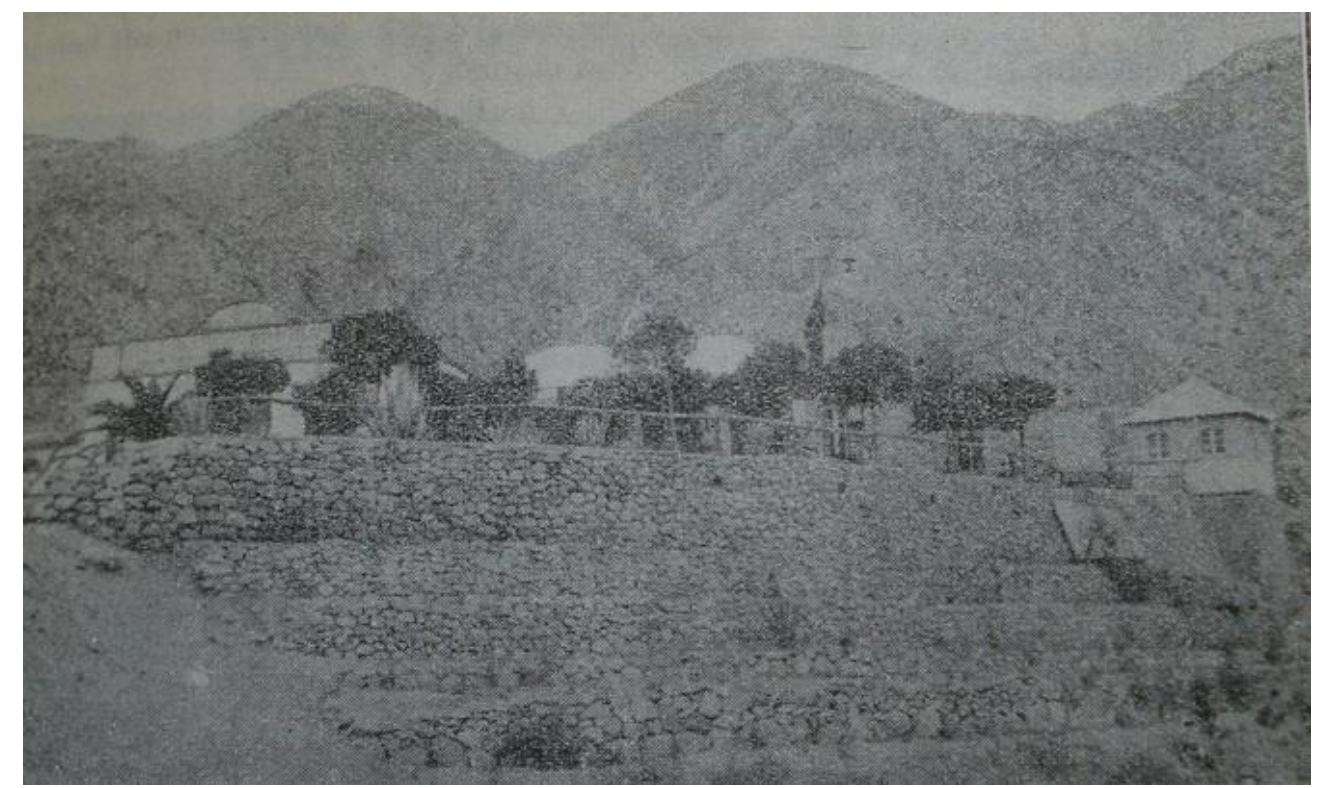

Figura 3: Posada de Quirós. Revista Mensual Ilustrada Luz y Fuerza, año II, n. ${ }^{0}$ 15, julio 1929, p. 22

Las arquitecturas, presumiblemente destinadas al hospedaje y a la gastronomía, se resolvieron también en piedra labrada del lugar, con cubiertas a dos y cuatro aguas de chapa sinusoidal. Completaba el conjunto un bosque de arbustos, aguaribayes, álamos y palmeras, configurando vistas de gran riqueza paisajística.

Respecto de la lógica de agrupamiento de las materialidades detectadas, se observa que su distribución en el territorio respondía a un partido utilitario, derivado de la disposición más eficiente para el funcionamiento del tren y sus equipamientos. $\mathrm{O}$ bien a un partido espontáneo, sin planificación previa, donde los edificios y viviendas se agrupaban según las necesidades de uso o de acuerdo con la topografía del terreno. En cualquier caso, se observa un carácter disgregado, que definía al espacio destinado a la vía del tren como eje ordenador de referencia.

En el análisis histórico del crecimiento del poblado, se verifican los principios expuestos por De Solà-Morales (1997), donde el conjunto manifiesta una «infraestructuración débil del territorio», la parcelación expone un «asentamiento de carácter repetitivo y ubicación aparentemente aleatoria», mientras que la edificación 
presenta una «apariencia en principio inexpresiva, destinada solo a la satisfacción de las necesidades con un grado de interdependencia indiferente», es decir, con ausencia de sentido global para el conjunto; cualidades todas que caracterizan las aglomeraciones suburbanas o difusas.

\subsection{El hotel termal}

El Ferrocarril Buenos Aires al Pacifico fue pionero en su promoción turística en Mendoza, al encarar desde la Compañía de Hoteles Sud Americanos Ltda., empresa subsidiaria del ferrocarril, la construcción de instalaciones para la provisión «de alojamiento y comida», como de equipamientos vinculados a las actividades de «balnearios y pistas de esquí, entre otros» (Lacoste 223a).

Ahora bien, en relación con la historia del balneario, hacia 1885 se construyó un conjunto de piletas para baños termales al costado del río Mendoza, en el lugar denominado «de la Boca del Río», que venía a suplir la carencia de instalaciones adecuadas para las inmersiones curativas, ampliamente difundidas por sus propiedades terapéuticas. No obstante, esta práctica usual de la época estaba en realidad reservada al reducido grupo de visitantes que se atrevía a llegar al lugar y descender por una empinada cuesta a la margen del río, donde se encontraban los manantiales termales. ${ }^{19}$ Detrás de las piletas se situó una precaria construcción en forma de L, presumiblemente de adobe, con cubierta a dos aguas. En una cota superior del cerro, más próxima a la ferrovía, se ubicaba el restaurant y a continuación un bloque destinado a habitaciones, que proporcionaban las comodidades mínimas para asegurar la permanencia en el lugar.

En 1902 se construyó «un formidable muro de defensa. Además, se cortó el talud natural de la margen derecha del río, para construir allí las nuevas piletas» (Lacoste 242a), dado que las anteriores habían sido arrasadas en 1898 por las crecidas estivales del río, junto con las antiguas instalaciones. Hacia 1905 la sección destinada a balneario propiamente dicho, en la parte baja de la ribera, se había mejorado: consistía en una sucesión de cuartos para baño a ambos lados del edificio, conectados por un pasillo central descubierto. La vinculación entre ellos y el casco

\footnotetext{
19 «En 1822 la Junta de Mendoza había declarado las termas como bienes de uso y goce de la comunidad. En 1870 ya se registraban viajes periódicos de personas que acudían a Cacheuta para bañarse en estas aguas. [...] Para ello abrían pozos en la arena y el ripio. En el verano, estos pozos desaparecían por las crecidas del río. Pero en la temporada siguiente volvían los visitantes para beneficiarse con estas aguas.» Lacoste, El Ferrocarril Trasandino 241.
} 
principal del hotel, más arriba, se resolvió con una extensa rampa para salvar las abruptas pendientes. Asimismo, se construyó la capilla hacia el extremo norte del conjunto y se ampliaron los cuerpos del edificio destinados a hall, habitaciones para huéspedes, restaurant y casino.

Para la explotación sistemática de las termas la Legislatura de Mendoza llamó a concurso mediante Ley 519/1910, para instalar un «establecimiento modelo», lo que resultó en una concesión por cuarenta años otorgada a una empresa privada en 1913, «integrada por Arturo Dácomo y Ramón Juyent, que posteriormente cedieron sus derechos y deberes a la Sociedad Anónima Termas de Cacheuta».20 Ese mismo año las instalaciones existentes fueron nuevamente remodeladas y ampliadas. ${ }^{21} \mathrm{se}$ cubrió con un lucernario de cristal y hierro la galería de los baños y se construyó la planta alta de las habitaciones. Los espacios exteriores también fueron objeto de mejoras: incorporaron jardines con senderos peatonales que delineaban parcelas de diseño ondulante (vinculado posiblemente a la tradición inglesa del paisajismo), con arbustos y árboles de diversas especies. Todas las circulaciones exteriores y las terrazas del hotel se coronaron con extensas balaustradas, que le dieron unidad al conjunto. En corto tiempo se incorporaron edificios de servicios, como el bloque de vivienda para personal, edificio de administración, cocina, lavandería y usina propia.

Respecto de los avances técnicos, que se tradujeron en el uso de materiales novedosos, se relevaron «tecnologías tradicionales de ladrillo y hormigón, [...] incorporación del cemento armado y el uso de vigas reticuladas en acero...». ${ }^{22}$ Junto con estas mejoras, el servicio de alojamiento contaba con 150 habitaciones y ofrecía

\begin{abstract}
... pastelería, panadería, dos amplios comedores, salón de lectura y escritura, una sala de música y un gran salón teatro-casino. [...] Dos ascensores llevan a los pasajeros desde el andén del ferrocarril hasta el patio del hotel y hasta la hermosa galería de los baños termales, donde están instalados los baños de inmersión, baños de vapor, salas de duchas, cuartos de masajes, consultorio, farmacia, peluquería de hombres y señoras. ${ }^{23}$
\end{abstract}

El Ferrocarril Pacífico asumió la tarea de promoción del hotel, a través de su Revista Mensual B.A.P. -Buenos Aires al Pacífico, como también los grandes diarios

\footnotetext{
${ }^{20}$ Lacoste, El Ferrocarril Trasandino 242.

${ }^{21}$ La empresa constructora y estudio de arquitectura Agustín Daverio \& Cía. recibió el encargo para la obra. Fundada en 1890, intervino «en la construcción de innumerables obras particulares de envergadura y obras de carácter público como las Casas Baratas del Barrio Cafferata» (Boletín de Obras Públicas de la República Argentina, n. ${ }^{\circ}$ 36, año 1937, p. 1102).

${ }_{22}$ Bianchi y Villalobos, «La modernidad en Mendoza...» 80.

${ }^{23}$ Revista Mensual BAP, n. ${ }^{\circ}$ 58, setiembre 1922, p. 45.
} 
de la época, que dieron a conocer las nuevas imágenes de la montaña, según apunta Lacoste:

Los ferrocarriles realizaron una activa labor para transformar la montaña en espacio social, especialmente apta para el turismo. Debieron enfrentar una tradición cultural que había condenado la cordillera a la marginación, manteniéndola como lugar desierto. Pero con su aporte al mejoramiento de la infraestructura, el equipamiento, las instalaciones y la superestructura turística, los ferrocarriles consagraron una actitud para la incorporación de este amplio territorio a la actividad socioeconómica de la región. ${ }^{24}$

Desde los orígenes de la estación balnearia y a lo largo de su historia, la disposición de los edificios respondió siempre a una configuración aterrazada, producto de las grandes pendientes a sortear para alcanzar las márgenes del río Mendoza. El partido se extendía sobre el terreno en una tipología estrecha y alargada de crecimiento, ajustada al espacio libre subsistente entre la vía del tren y la ribera. Este esquema longitudinal respondía a un eje estructurante del conjunto: la ferrovía. Por otra parte, el propio edificio del hotel se configuraba como telón de fondo de un segundo espacio de relevancia, por lo que quedaban definidas dos calles como espacios emblemáticos, que articulaban la composición.

En una cota superior, la calle de carácter público, junto a la vía, que recibía y permitía la socialización inaugural de los visitantes. En el nivel inferior, una calle propia del hotel, que las sucesivas publicidades nombran como la «rambla de paseo», y se constituyó en el espacio más importante al ser aglutinador de las prácticas de sociabilidad veraniega: charlas, caminatas, partidas de cartas, encuentros de té, lugar de celebraciones oficiales, sitio de juego y encuentro de niños y también con la función de extenso mirador. Además, vinculaba el cuerpo central del hotel con todas las actividades y usos que se ofrecían al aire libre. ${ }^{25}$

Este esquema de concepción espacial del hotel, de desarrollo paralelo al trazado ferroviario, fue una constante en todas las remodelaciones y ampliaciones a que fue sometido el balneario, presumiblemente para ganar las mejores vistas hacia el río y los cerros, de manera que según lo requiriesen nuevas necesidades de espacio o servicios para albergue, la lógica de adición de nuevos cuerpos buscaba preservar esta linealidad (Figura 4).

\footnotetext{
24 Lacoste, El Ferrocarril Trasandino 223.

${ }_{25}$ De ellas, destacan juegos de bochas, partidos de tenis, cabalgatas y la inmersión en la piscina descubierta, todas accesibles desde la rambla de paseo.
} 


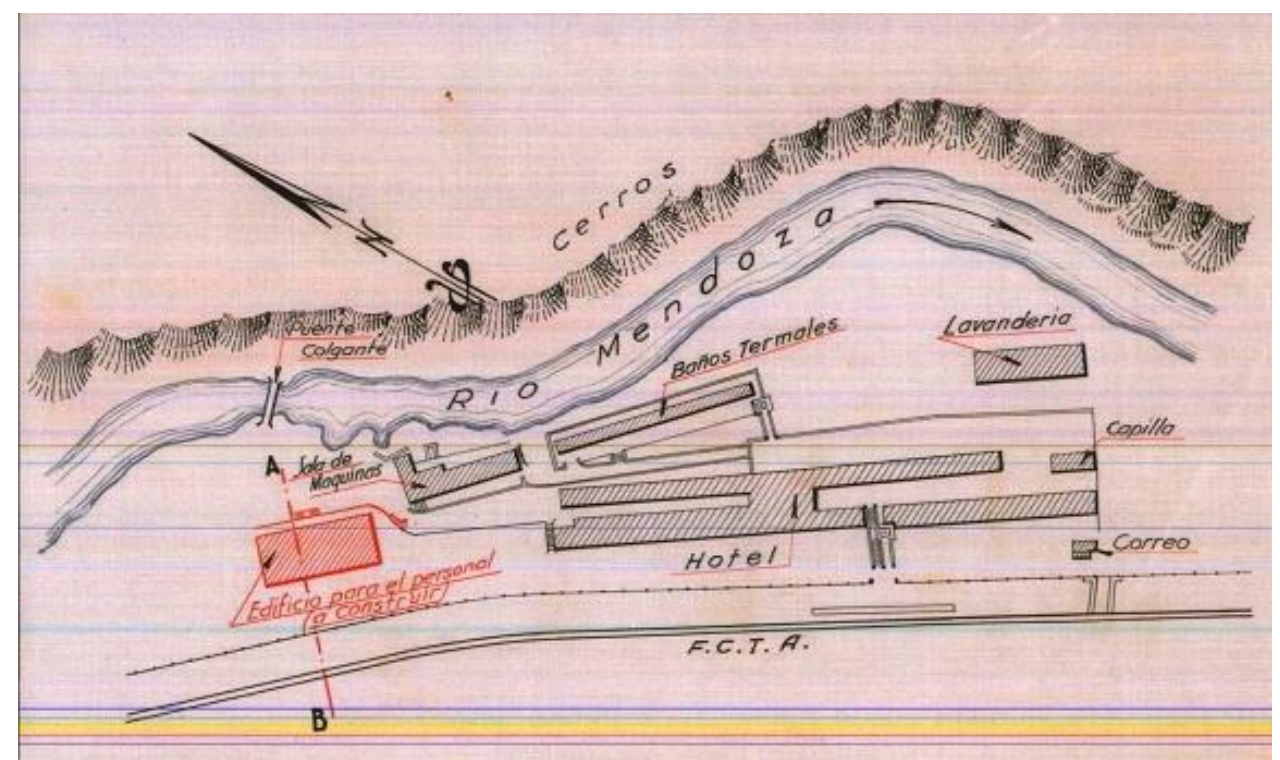

Figura 4: Planta general del balneario (1916). Archivo AHTER (Incihusa-Conicet). Plano «Hotel y Balneario Termas de Cacheuta. Edificio para personal. Plano de ubicación»

(fragmento).

Esta condición se mantuvo también para los equipamientos del hotel ubicados en las cotas más bajas del terreno, cercanas al cauce natural del río, como los cuartos de baño propiamente dichos (dado que las aguas termales se captaba desde su misma naciente), la piscina descubierta (construida en 1934) o los anexos de servicio, como la lavandería; aun cuando la construcción en la parte baja de las márgenes constituyera un emplazamiento de riesgo, tal como lo demostraron los sucesivos aluviones de 1898, 1913, 1920 y 1934.

Es de destacar la condición colonizadora que alcanzó el hotel, en el sentido de generar arraigo de las personas al lugar; ya sea por la gran cantidad de empleados que demandaba su funcionamiento, ${ }^{26}$ quienes tenían su residencia permanente en las mismas dependencias del hotel o en el poblado, como por la afluencia continua de visitantes, lo que provocaba un hormigueo incesante de personas, sobre todo en la temporada de verano. Por caso, la estación Cacheuta del FCT registró en 19149823 pasajeros despachados y 16.283 pasajeros recibidos. ${ }^{27}$ Hacia 1916 «se registró un movimiento de 6347 pasajeros, y el conjunto del año cerró con un promedio mensual

${ }^{26}$ Cerca de 130 personas prestaban sus servicios en el hotel entre mucamas, mozos, pasteleros, cocineras, médicos, enfermeros, lavanderas, bedeles, peluquero, boticario, jardineros, técnicos, personal de mantenimiento, administrativos y gerencia, según pudo relevarse en fotografías históricas. ${ }_{27}$ A título comparativo, la estación cabecera de la ciudad de Mendoza registró en el mismo año 31.085 pasajeros despachados y 34.564 pasajeros recibidos. Tabla «Ferro Carril Buenos Aires al Pacífico. Pasajeros despachados y recibidos de las estaciones de la provincia de Mendoza durante el año». Gobierno de Mendoza. Anuario de la Dirección de Estadísticas de la Provincia de Mendoza, año 1914, p. 379 (Mendoza: Ed. Oficial, 1915). 
de 2.531 personas. En total, en 1916 llegaron a Cacheuta más de 30.000 pasajeros, cifra que se reiteró también en 1919» (Lacoste 248a).

La estación termal constituyó un agente significativo para la generación de empleo y la promoción de actividades económicas de la población local, como por ejemplo: cultivo de frutas y hortalizas, cría de ganado vacuno, porcino y de aves de corral para consumo, cría de ganado mular y caballar para cabalgatas e instalación de tambo para la producción de quesos y leche, entre otros.

Durante la primera etapa de su historia, la única manera de acceder al hotel era por medio del ferrocarril. Para llegar a Cacheuta, el tren demoraba veinticuatro horas desde Buenos Aires y dos horas desde Mendoza: «La estación se ubicaba a unos centenares de metros del hotel, pero en temporada de gran afluencia de público, se detenía frente al mismo» (Lacoste 247a), lo que contribuyó a propiciar el uso de la calle pública del hotel como el gran espacio de socialización inicial de los recién llegados.

\section{Promoción turística y producción hidroeléctrica en el enclave}

Hasta este momento de la historia del valle se detecta la coexistencia de dos importantes agentes responsables de las modificaciones introducidas en el territorio: el Estado, propietario de una fracción de 46 ha, que había concesionado la explotación del hotel termal; y la empresa del FCT, con la instalación de los equipamientos del tren.

Las acciones encaradas desde 1925 en materia turística y de desarrollo energético propiciaron una segunda etapa de ocupación del territorio, con el establecimiento de nuevas infraestructuras: el camino carretero por una parte y la central hidroeléctrica de la Empresa Luz y Fuerza por otra, que había comprado al ferrocarril Gran Oeste Argentino- Buenos Aires al Pacífico dos fracciones de tierra: una de 12 ha y $5000 \mathrm{~m}^{2}$ y otra de 10 ha y $4177 \mathrm{~m}^{2}$, para la construcción del dique derivador y la usina generadora de energía. ${ }^{28}$

\footnotetext{
${ }^{28}$ La venta de los terrenos se produjo en 1910. Hacia 1915 el dique de toma estaba prácticamente finalizado, según consta en el archivo del EPRE, pero las obras se paralizaron por una «caducidad en la concesión acordada a la empresa» producto de un pleito generado en la gestión del gobernador Francisco Álvarez (1914-1917). José Aguilar, «Memoria presentada por el Ministro de Industrias y Obras Publicas Dr. José E. Aguilar a la Honorable Legislatura de Mendoza. 1926-1927» (Buenos Aires: Colombatti y Cía. Ltda., 1928).
} 
En 1926 por Decreto 362 se aprobó el final de obra de la «nueva» central hidroeléctrica en Cacheuta, ${ }^{29}$ el trazado de la línea de alta tensión y la instalación de transformadores, interruptores y tableros en la sub usina de la calle San Martín, en la ciudad de Mendoza. La central, inaugurada el 24 de mayo de 1926, contaba con dique de embalse, filtros, piletas desarenadoras, canal derivador, cámara de carga y sala de máquinas, entre otras infraestructuras, que demandaban presencia permanente de operarios para su control y puesta a punto, particularmente en dos sectores: el dique de toma (situado en el km 40 del FCT) y la sala de máquinas (en el km 37,2); donde se asentó el barrio obrero más importante; lo que afianzó, junto con la estación balnearia, el arraigo definitivo del poblado fundacional de Cacheuta.

De las arquitecturas surgidas del emprendimiento hidroeléctrico, destacan la usina propiamente dicha y el chalet para el personal jerárquico, que la empresa edificó unos $120 \mathrm{~m}$ hacia el sureste de la central. El edificio de la usina respondía a un partido eminentemente utilitario, resuelto en un volumen de planta rectangular $(13,20 \mathrm{~m} \times 24,50 \mathrm{~m})$ con tipología de nave de triple altura, con cubierta de chapa a cuatro aguas de suave pendiente; que alojaba dos turbinas con sus generadores eléctricos, cada una de $3000 \mathrm{~kW}$ de capacidad instalada. $3^{\circ}$ Adosado a él, un volumen de menor altura acompañaba toda la longitud de la usina y albergaba la sala de distribución. El edificio estaba materializado con sillería de piedra labrada de la zona. La cubierta, soportada por cerchas de madera, contaba con un puente grúa de mantenimiento que se desplazaba en toda la longitud de la nave, constituido sobre perfiles y rieles de acero.

El barrio de operarios se ubicó, al igual que en los asentamientos previamente analizados, en un promontorio elevado delimitado por un codo del río, al norte de la usina. $\mathrm{Su}$ arquitectura presentaba una agrupación sin jerarquización aparente, solo enlazada por la vía del tren, donde destacaban volúmenes resueltos en piedra con cubiertas a cuatro aguas de pronunciada pendiente, alternados con galpones utilitarios y depósitos con cerramientos y cubiertas de chapa sinusoidal.

${ }^{29}$ La construcción de la primera usina en el valle fue gestionada por el ingeniero Carlos Fader en 1899: por ley 117 recibió el permiso de aprovechamiento de las aguas del río Mendoza para la generación de energía. Hacia 1910 y luego de su muerte, su hijo Fernando se hizo cargo de la central y las obras faltantes, hasta su puesta en servicio. Finalmente, en 1913 una creciente del río Mendoza arrastró las instalaciones y la empresa se declaró en quiebra (Cien años de vida mendocina. Centenario diario «Los Andes». 1882- 1982. [Mendoza] Los Andes, 1982, p. 61).

${ }^{30}$ Algunos datos ilustrativos sobre la nueva Usina Hidroeléctrica Cacheuta y demás instalaciones de la Empresa Luz y Fuerza SA en la provincia de Mendoza, República Argentina. Empresa Luz y Fuerza, 1926, p. 29. 
En tanto que el chalet, en lenguaje pintoresco, se organizaba a partir de una planta rectangular y albergaba las funciones de vivienda para personal de la administración y oficinas técnicas. Con cubiertas quebradas de fuertes pendientes en chapa sinusoidal y con la planta baja sobre elevada respecto del nivel del terreno, resolvió su membratura en sillería de piedra labrada. Se ubicaba en un cerro frente a la central, desde donde tenía dominio visual de esta y del río. El conjunto fue completado por un bosque de pinos y acacias, de trazado orgánico, junto al chalet. Senderos para caminatas y una fuente ornamental contrastaban con el paisaje industrial predominante en el sitio (Figura 5).

El verano de 1934 fue testigo de la creciente más importante que se produjo sobre el río Mendoza en todo el siglo, ${ }^{31}$ que al llegar al valle de Cacheuta, arrasó con el sector de los baños termales situados en la margen del río, causando serios daños materiales y pérdida de vidas humanas, tanto en el hotel y la nueva central como en las secciones aguas abajo. $3^{2}$

${ }^{31}$ Un rodado deslizado desde un ventisquero generó un dique natural a las aguas del río Plomo, afluente del Mendoza. La presión del dique empujó violentamente la obstrucción, liberando el torrentoso caudal, lo que ocasionó la avenida.

${ }^{32}$ Como consecuencia del aluvión se interrumpen los servicios del FCT indefinidamente, la Sociedad Anónima concesionaria del hotel termal ofrece al gobierno rescindir el contrato de concesión y someter a decisión arbitral las consecuencias legales y económicas de los hechos producidos, en virtud de no poder continuar la explotación del balneario por su estado de deterioro. El gobierno resuelve la recisión del contrato en 1936 pero sin aceptar la pérdida de las termas, por su parte la empresa concesionaria no consentía la obligación de reconstruir el balneario. Tras un extenso pleito la Provincia es condenada a pagar en 1937 la suma de \$4.617.277,27 m/n a la Sociedad Anónima Termas de Cacheuta y decide entregar la concesión del hotel a Enrique Balbi, por Decreto 460/1937, y reanudar los servicios hoteleros previo acuerdo de «completar las obras de reparación y defensa de las construcciones que fuesen necesarias para el servicio de los baños termales» (inauguradas recién en 1944) y de mantener el funcionamiento de todo el balneario «para una capacidad mínima de ciento veinte pasajeros, con alojamiento, pensión completa y baño termal». Guillermo Cano, «Tres años de gobierno» (Mendoza: Imprenta Oficial, 1938). 


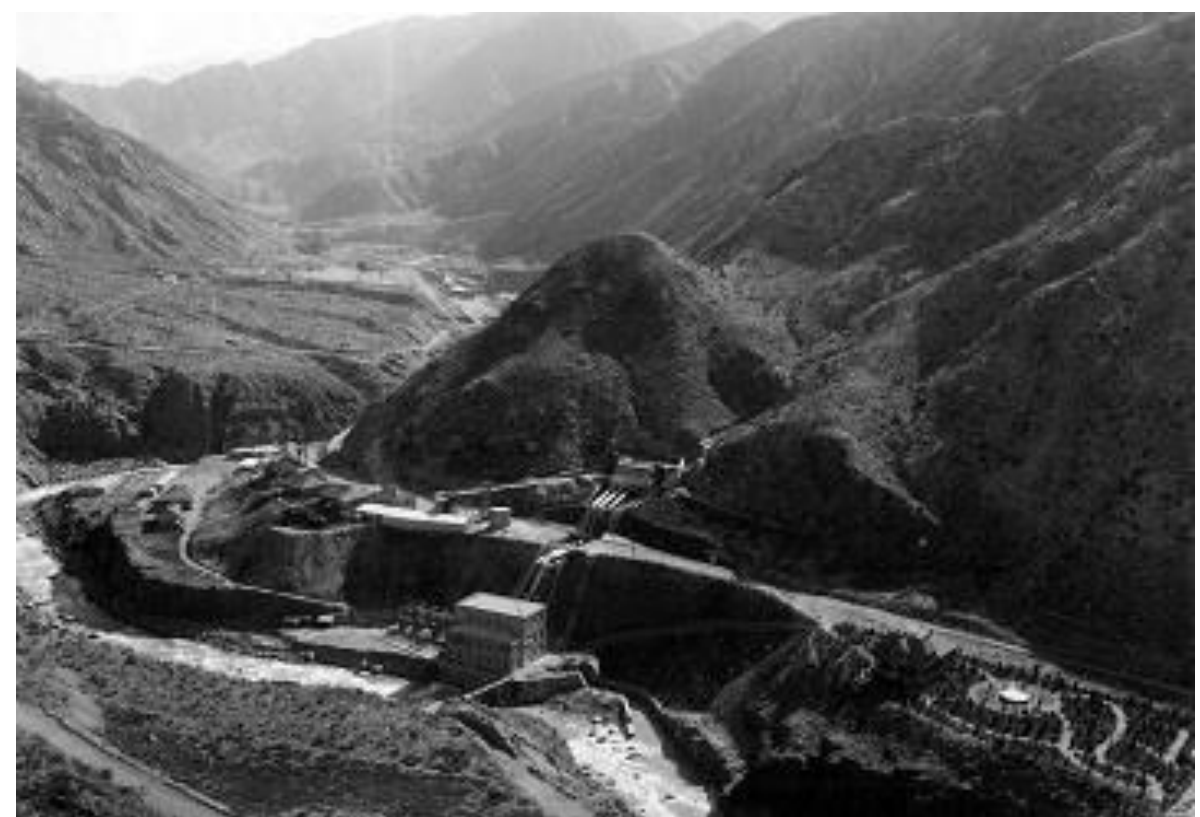

Figura 5: Vista general de la usina, el barrio obrero y chalet del personal jerárquico (1926c.). Galileo Vitali, Hidrología Mendocina: Contribución a su Conocimiento. (Mendoza: Talleres Gráficos D’Accurzio, 1940), 43.

El camino carretero hacia Cacheuta, inaugurado en 1928, había sufrido igualmente daños severos, pero fue reconstruido por la Dirección Provincia de Vialidad (creada por ley 1.019 en 1933). La política turística implementada por los gobiernos neoconservadores en Mendoza alentó este desarrollo vial, junto con la pavimentación de carreteras existentes y la construcción de hoteles de turismo. Para Raffa (2018) el rol desempeñado por la Dirección Provincial de Vialidad fue determinante a la hora de vincular áreas suburbanas con la ciudad, por medio de un plan sistemático de construcción de puentes y caminos, financiado con fondos provinciales y nacionales. De esta manera, facilitaba el acceso a las villas de montaña, acercándolas simbólica y materialmente al conjunto de la población, a la vez que completaba la oferta del FCT que hasta ese momento había monopolizado el transporte de personas y bienes desde y hacia el valle.

Debe destacarse que, en este contexto, donde las prácticas turísticas modernas situaban a las carreteras en el centro de la escena, el automotor «estaba llamado a desempeñar un rol capital en el incremento del turismo» y era considerado «un elemento insustituible para el tiempo libre», según apunta Ospital.33 Piglia sostiene que, avanzada la década de 1930, se difundieron imágenes de las prácticas recreativas deseables en automóvil, vinculadas estrechamente a un sentimiento patriótico,

33 Silvia Ospital, «Turismo y territorio nacional en Argentina. Actores sociales y políticas públicas, 1920-1940». Estudios Interdisciplinarios de América Latina y el Caribe, 16 (2005): 63-84 
promoviendo un «modelo de viaje en el que el objetivo era el propio recorrido, más que el destino final» y buscaban enlazar «una serie de hitos y vistas patrióticos, ya fueran estos rasgos naturales, restos del pasado nacional o colonial o muestras de la pujanza y el progreso nacional». 34

En sintonía con esta nueva mirada respecto del automóvil y la carretera, en 1937 se habilitó un camping sobre terrenos fiscales en Potrerillos, a $15 \mathrm{~km}$ aguas arriba del poblado de Cacheuta, con capacidad para 150 personas (Raffa 2020) y en 1941 se licitó la obra de asfaltado entre las localidades cordilleranas de Blanco Encalada y Cacheuta. Además se inauguró el Hotel de Potrerillos y a partir de 1943 el Estado provincial fomentó la urbanización del valle homónimo, bajo la premisa que la gestión de gobierno debía crear «nuevos atractivos para los visitantes, proporcionando las comodidades necesarias para que los hermosos parajes cordilleranos cuenten con los elementos indispensables para convertirse en gratas estaciones» de permanencia y descanso. 35

Las políticas democratizadoras en materia turística impactaron también en el poblado obrero de la central hidroeléctrica y el uso de sus espacios: aquellos que antiguamente se concibieron como funcionales a propósitos operativos y de mantenimiento de la central se convirtieron, con las nuevas modalidades de turismo, en espacios de ocio destinados a los empleados. La empresa Luz y Fuerza (que luego de una reestructuración interna en 1931 se denominó Compañía de Electricidad los Andes-CELA) incorporó instalaciones de un club social en el predio del barrio; con pista de baile, cancha de bochas y piscina al aire libre con agua termal (Figura 6).

El aumento sostenido del parque automotor a partir de la década de 1920 provocó la mejora y multiplicación de caminos de acceso, con nuevas infraestructuras que permitieron recorrer las localidades de montaña con relativa comodidad.

34 Melina Piglia, «Turismo en automóvil en Argentina (1920-1950)», Tempo Social, 30 (2018): 87-111. 35 Adolfo Vicchi, «Labor gubernativa 1941-1944» (Mendoza: Imprenta Oficial, 1944). 


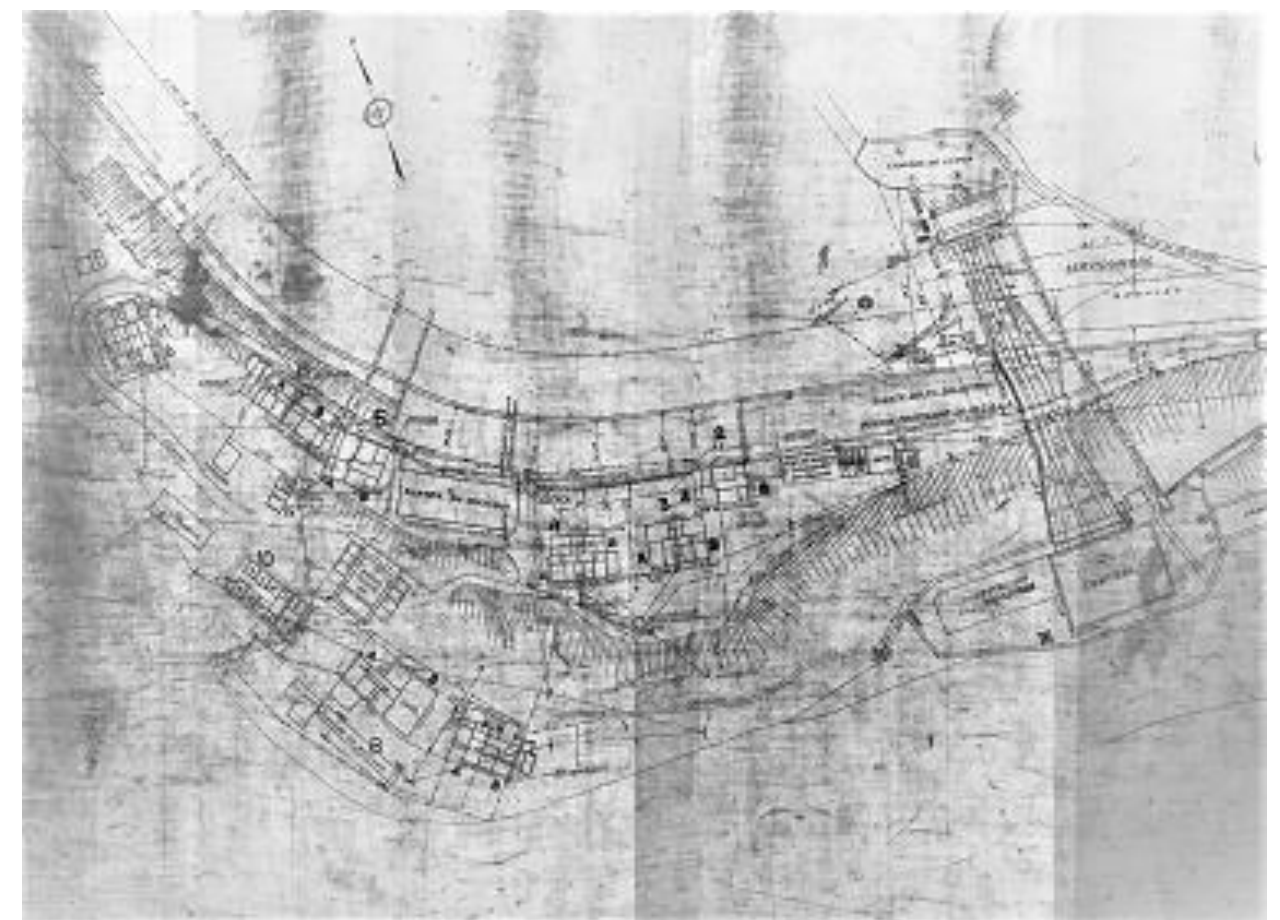

Figura 6: Planimetría del barrio obrero que muestra la disposición de las viviendas y espacios de trabajo existentes junto con los nuevos espacios destinados a esparcimiento (1943). Archivo del EPRE. Plano «Cacheuta km 37- Plano de situación y ferrocarril» (fragmento).

Este cambio en la modalidad del transporte, relegó al poblado de Cacheuta a una condición de aislamiento: la traza del camino carretero, desplegada en una cota de terreno por encima del tendido ferroviario, hizo que este perdiera visibilidad. Por otra parte, la ruta no seguía un itinerario paralelo a la vía del tren, sino que se abría hacia el oeste ni bien trasponía el sector de la estación. De este modo, cercenaba la acción simbólica de enlazar las dos partes del poblado, destino que, desde sus atributos espaciales, morfológicos, funcionales y sociales como espacio emblemático, había asumido exitosamente la traza del ferrocarril.

Luego de la nacionalización de los ferrocarriles en 1944 fue posible la reactivación del FCT y el Estado comenzó a parcelar tierras fiscales, con la venta de pequeños lotes en el poblado de Cacheuta (Lacoste 2013). Hacia 1949 comenzaron a construirse las primeras viviendas, sin embargo, la lógica del camino carretero, perteneciente a otro momento histórico y otra visión de mundo, no logró amalgamar las funciones y espacialidades que había instaurado la infraestructura ferroviaria. En 1953 la Dirección Provincial de Vialidad construyó un puente colgante para tránsito peatonal, que, paralelo al antiguo puente ferroviario, unía el sector antiguo de la estación con el promontorio norte donde se ubicaban la escuela y el cementerio. El puente, de $112 \mathrm{~m}$ de longitud y 1,6 m de ancho, cruzaba a una altura de 15 metros 
sobre el cauce del río Mendoza. Esta medida coronó el conjunto de inversiones que operaron en el valle durante la primera mitad del siglo $\mathrm{xx}$, consolidando su posicionamiento como territorio propicio para el establecimiento de capital económico y humano.

Lo expuesto permite comprender la magnitud y complejidad de actuaciones que sentaron las bases del enclave Cacheuta como suburbio moderno; devenido en destino turístico, actuaciones iniciadas con el cambio de siglo y marcadas por los avances tecnológicos y la idea de progreso, estimulados a partir de la llegada de infraestructuras como el tren y la carretera (Figura 7).

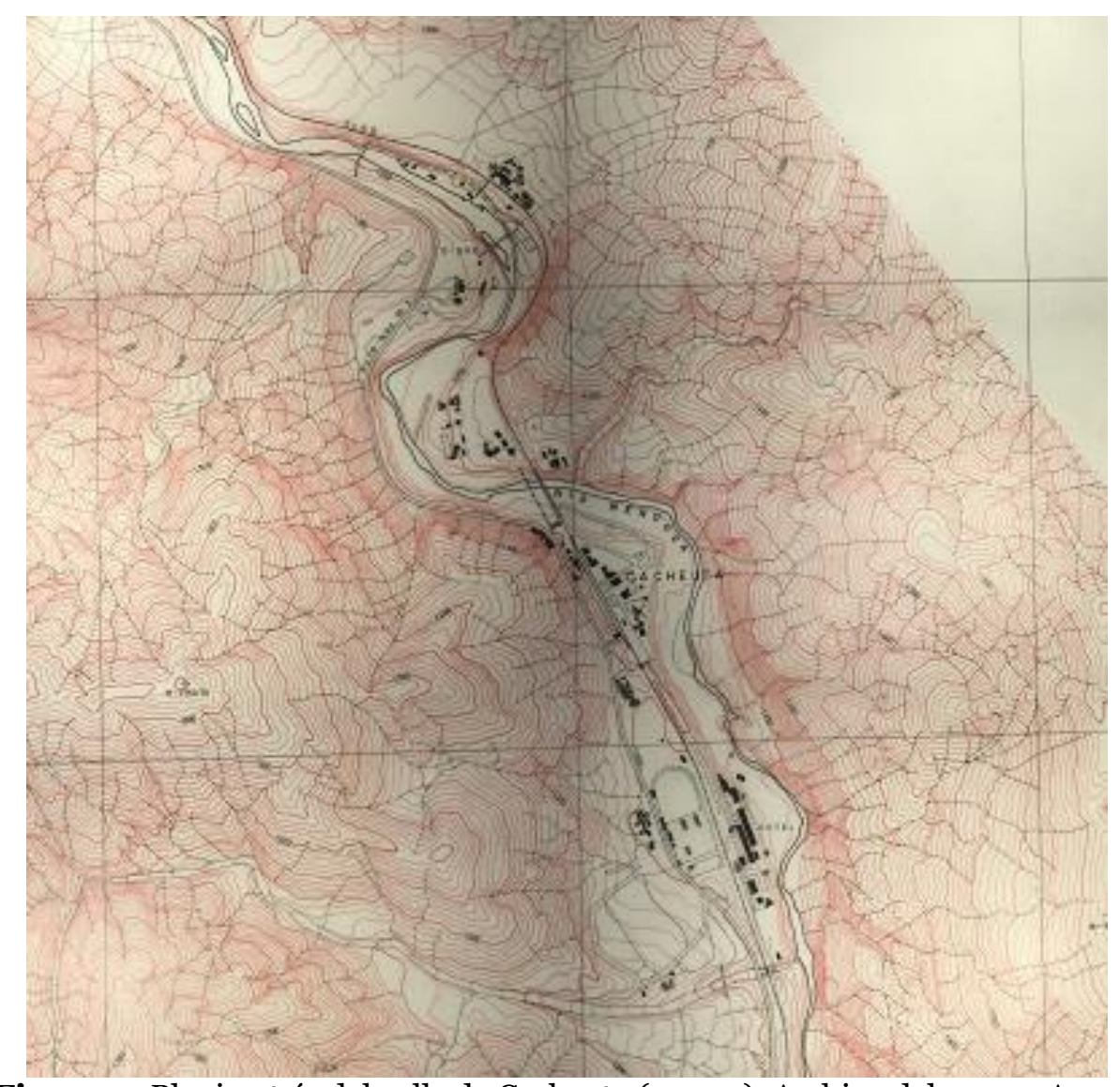

Figura 7: Planimetría del valle de Cacheuta (1950c.). Archivo del EPRE. «Agua y Energía Eléctrica. Departamento Estudios y Proyectos. Zona Cacheuta. Planialtimetría aerofotogramétrica» (fragmento).

La solemnidad y belleza del paisaje de montaña, junto con las políticas de promoción turística y la inversión privada, condensaron en un paraje de características únicas, de gran riqueza ambiental y paisajística, que se mantuvo prácticamente invariable en el segmento histórico analizado.

\section{Consideraciones finales}


Los avances alcanzados hasta el momento permiten confirmar que el asentamiento de Cacheuta constituye un ejemplo significativo producto de la modernización de fin de siglo XIX. Las actividades pioneras observadas en el sector, como el termalismo, la explotación de hidrocarburos y la generación de energía hidroeléctrica, dan cuenta de la compleja trama de intereses que operaron en el valle, transformando el escenario de la montaña - primitivamente indómito- en un enclave generador de riquezas.

La presencia del FCT posibilitó un notable adelanto en la región, con actuaciones que replicaron las experiencias de los inmigrantes europeos (en su mayoría ingleses vinculados con las obras del tren), lo que transformó la fisonomía del valle. Estas acciones elevaron el sitio, vinculado a la explotación de aguas termales, a la condición de destino turístico de renombre del centro oeste de Argentina, en el segmento temporal 1913-1934. Sumado a ello, se incorporaron actividades afines al aprovechamiento de la estación termal, surgidas del poblamiento paulatino de la zona: correo, telégrafo, pequeños comercios y emprendimientos agropecuarios, entre otras.

Al igual que en otros poblados industriales, el FCT actuó como catalizador de distintos procesos; al facilitar las comunicaciones acortando los tiempos, permitir el arribo de nuevas tecnologías y saberes, promover el poblamiento y asegurar el termalismo en un primer momento; devenido luego en turismo, en el sentido amplio del término. Así lo refleja, por un lado, el balneario de Cacheuta con equipamiento y servicios acordes a los gustos de la aristocracia finisecular, que garantizaban un abanico de actividades sociales y recreativas en un marco de confort y elegancia. Por otro, el surgimiento de albergues turísticos de menor rango, como la posada Quirós, que se ofrecía en simultáneo como destino alternativo al establecimiento termal, o más adelante en el tiempo el club social de la Compañía de Electricidad de los Andes, concebido para satisfacer las demandas de sus empleados.

En este contexto, el valor que adquirió el trazado ferroviario como espacio emblemático es innegable, tanto para el antiguo poblado y el conjunto obrero de la central hidroeléctrica, en que tal espacio había definido una zona de circulación, sector de concentración de servicios (asociados al tren o a la operatividad de la usina) y a la vez ofrecía el espacio público de intercambio; como para el hotel, que heredó de esta infraestructura una configuración oblonga. Esta distribución permitió por una 
parte la apropiación de la barranca natural del río, con una lógica de crecimiento característica, sobre terrazas. Por otra parte, hizo posible concebir un espacio propicio para la socialización, inmerso en un paisaje de excepcional belleza: encarnaba la singularidad de la calle suburbana como ordenador de las arquitecturas e infraestructuras, con la doble característica de recorrido y como soporte de la edificación.

$\mathrm{El}$ artículo permite confirmar que los poblados relevados en distintos puntos del valle, cercanos entre sí; surgieron en condiciones físicas adversas, a las que respondieron con gran adaptabilidad y acompañando de manera silente el desarrollo del área estudiada, con un patrón disgregado en el terreno y con construcciones bajas, pero siempre dispuestas en puntos estratégicos definidos por el curso tortuoso del río o al abrigo de los faldeos montañosos. Esta configuración de suburbio comparte un carácter espontáneo, que no daba respuesta a una planificación preliminar o estanca, sino que se identificó por encarnar formas orgánicas y funcionales. Se trata de un tipo de ordenación suburbana de carácter difuso, que hace gala de la armonía entre el hábitat humano y el contexto natural que lo rodea y define.

Del análisis se desprende que las infraestructuras ferroviaria y carretera supusieron no solamente un incremento sustancial en la calidad de los servicios y una mayor afluencia de visitantes; sino que constituyeron - sobre todo con el aporte del FCT - un factor decisivo en las dinámicas de poblamiento, al tomar relevancia en la fundación de un nuevo poblado con la consiguiente incorporación de territorios productivos antes ignorados, al mapa económico provincial y nacional.

$\mathrm{Al}$ profundizar en los procesos de fundación de los asentamientos y en su evolución de crecimiento suburbano, se hace evidente una lógica caracterizada por un ordenamiento secuenciado de tres procesos: la urbanización en primera instancia; con la instalación de las infraestructuras esenciales, pertenecientes al tren; luego la parcelación, con la definición de límites y asignación de propietarios a los solares y finalmente la implantación de las arquitecturas (estación, viviendas, comercio, hotel).

Hacia el final del arco temporal propuesto para el abordaje, la incursión de la ruta carretera interrumpió esa natural dinámica de conformación de los espacios y se observa, en simultáneo con la aparición de las infraestructuras viales, la parcelación sistemática y el surgimiento de nuevas arquitecturas residenciales. Este momento 
evidencia una mayor gravitación del accionar estatal en el proceso de difusión turística del enclave, con nuevas intervenciones hoteleras o bien desarrollo de la trama vial, específicamente diseñada para facilitar la conexión con el destino y mejorar la oferta turística.

Sin embargo, se observa que las cualidades del enclave permanecieron, en el período estudiado, prácticamente invariables, lo que condensó en un paraje de montaña de características ambientales de gran relevancia, instituido como testimonio material y espacial de una forma particular de apropiación del territorio. Esta forma de apropiación es consecuencia directa de una concepción moderna de la vida suburbana, que buscó mejorar las condiciones naturales del lugar para adaptarlo al desarrollo de las actividades humanas, sirviéndose de nuevas tecnologías y saberes y guiada por el espíritu visionario propio del positivismo finisecular.

\section{Obras Citadas}

\subsection{Fuentes}

Aguilar, José, Memoria presentada por el Ministro de Industrias y Obras Públicas Dr. José E. Aguilar a la Honorable Legislatura de Mendoza. 1926-1927. Buenos Aires: Colombatti y Cía. Ltda., 1928.

Argentina. Ministerio de Obras Públicas. Boletín de Obras Públicas de la República Argentina, n. ${ }^{\circ}$ 36, año 1937. Buenos Aires: Ministerio de Obras Públicas.

CeDIAP- Centro de Documentación e Información de Arquitectura Pública. Título del documento: «Reparaciones y obras sanitarias. Planta y corte $\mathrm{AB}$ ». Identificación única: 1826-oooo1. Observaciones: digitalizado. Autor: ix> zona. Fecha: 1931-07-01. Tipo: instalación sanitaria / incendio. Escala: 1:100 Disponible en http://portalcdi.mecon.gov.ar/cgi-

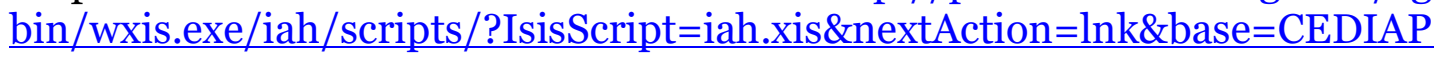
\&lang=es\&exprSearch=1826\&indexSearch=CO\&conectSearch=AND\&exprSea $\underline{\mathrm{rch}=\mathrm{PLANO} \text { \&indexSearch }=02}$

Cano, Guillermo. Tres años de gobierno. Mendoza: Imprenta Oficial, 1938.

Dirección de Estadísticas de la Provincia de Mendoza. Anuario de la Dirección de Estadísticas de la Provincia de Mendoza (año 1914). Mendoza: Ed. Oficial, 1915 .

Empresa Luz y Fuerza. Revista Mensual Ilustrada. [Mendoza, 1928-1930].

- - - (1926) Algunos datos ilustrativos sobre la nueva Usina Hidroeléctrica Cacheuta y demás instalaciones de la Empresa Luz y Fuerza SA en la provincia de Mendoza, República Argentina. Buenos Aires, s/f.

Ferrocarril Buenos Aires al Pacífico. Revista mensual bap. [Buenos Aires, 1921-1937].

Los Andes. Cien años de vida mendocina. Centenario diario «Los Andes». 1882-1982. Mendoza: diario Los Andes, 1982. 
Moretti, Graciela, «Los puentes de Cacheuta», en: Suplemento de Arquitectura. Diario Los Andes, Mendoza. 29/11/2016. Versión digital, consultada en: https://www.losandes.com.ar/article/los-puentes-de-cacheuta

S. A. Termas de Cacheuta, Libro de Oro de Cacheuta. Buenos Aires: Compañía General Fabril Financiera Talleres Gráficos, 1930.

s/d, «Pionera en promover el turismo en Misiones en el siglo xx», en El Territorio, Misiones, 15/10/06. Digital, Disponible en https://www.elterritorio.com.ar/pionera-en-promover-el-turismo-enmisiones-en-el-siglo-xx-8198436787434384-et

Vicchi, Adolfo, Labor gubernativa 1941-1944. Mendoza: Imprenta Oficial, 1944.

Vitali, Galileo, Hidrología Mendocina: Contribución a su Conocimiento. Mendoza: Talleres Gráficos D’Accurzio, 1940.

\subsection{Bibliografia}

Barthes, Roland. La cámara lúcida. Nota sobre la fotografía. Barcelona: Paidós, 1999.

Berman, Marshall. Todo lo sólido se desvanece en el aire. La experiencia de la modernidad. Madrid: Siglo Veintiuno Editores, 1988.

Bianchi, P. y Villalobos, A. M. (2015). Estudio del sistema hídrico del río Mendoza. Canales Zanjón y San Martín. Diagnóstico de capacidades y aportes al paisaje. Etapa 1: Luján de Cuyo y Godoy Cruz. (Resultados del proyecto de investigación Convocatoria 2013-2015, icau, inédito). FAUyD, Universidad de Mendoza.

Bianchi, Pablo y Villalobos, Ana María, «La modernidad en Mendoza (1890-1930): el enclave Cacheuta como testimonio de montaña». Anales de Investigación en Arquitectura, 9 (2019): 69-88.

Booth, Rodrigo; Cáceres, Gonzalo y Sabatini, Francisco, «La suburbanización de Valparaíso y el origen de Viña del Mar: entre la villa balnearia y el suburbio del ferrocarril (1870-1910)», en Las puertas al mar. Consumo, ocio y política en Mar del Plata, Montevideo y Viña del Mar (33-50). Mar del Plata: Biblos, 2002.

Boyer, Marc, «El turismo en Europa, de la edad moderna al siglo xx». Historia Contemporánea, 25 (2002): 13-31.

Bruno, Perla, «Tradición y modernidad en la concepción del territorio turístico en el litoral bonaerense, Argentina 1920-1950». Revista Iberoamericana de Urbanismo, 2 (2009): 4-16. Disponible en http://hdl.handle.net/2099/12258

Butler, Richard, «Evolution of tourism in the Scottish Highlands». Annals of Tourism Research, 12 (1985): 371-391.

Corbin, Alain. El territorio del vacío. Occidente y la invención de la playa (17501840). Barcelona: Mondadori, 1993.

Cueto, Adolfo; Romano, Aníbal y Sacchero, Pablo. Historia de Mendoza, desde los primitivos habitantes hasta nuestros días. Diario Los Andes, Fascículo 1, 1991.

De Fusco, Renato. Historia de la arquitectura contemporánea. Madrid: Celeste Ediciones, 1992. 
De Solà-Morales Rubió, Manuel. Las formas de crecimiento urbano. Barcelona: Edicions UPC, 1997.

Gutiérrez, Ramón. Arquitectura y urbanismo en Iberoamérica. Madrid: Cátedra, 1983.

Lacoste, Pablo. El ferrocarril Trasandino y el desarrollo de los Andes centrales argentino-chilenos (1872-2013) Santiago de Chile: idea, 2013a

- - - - «El Ferrocarril Trasandino y la invención de la montaña como espacio social». Entrepasados, 24 (2004b): 177-198.

-_-_- Grandes obras de Mendoza. Aportes para el estudio de la historia del turismo y la Ingeniería. Mendoza: Diario UNO, 1998c.

Larrinaga, Carlos, «Cestona en los orígenes del termalismo vasco (1776-1833). La conformación de un establecimiento de baños en Guipúzcoa». Agua y Territorio, 6 (2015a): 22-33.

Larrinaga, Carlos, «El turismo en la España del siglo xix». Historia contemporánea, 25 (2002b): 157-179.

Marradi, Alberto; Archenti, Nélida y Piovani, Juan Ignacio. Metodología de las ciencias sociales. Buenos Aires: Emecé, 2007.

Michieli, Teresa. Antigua historia de Cuyo. San Juan: Ansilta Editora, 1994.

Ospital, Silvia, «Turismo y territorio nacional en Argentina. Actores sociales y políticas públicas, 1920-1940». Estudios Interdisciplinarios de América Latina y el Caribe, 16 (2005): 63-84.

Pastor, Gabriela y Raffa, Cecilia, «Huellas de relatos en movimiento. Los patrimonios emergentes del itinerario argentino-chileno de casas de postas: la ruta mendocina». Nicoletti, M. Andrea y Nuñez, Paula (comps.). Araucanía Norpatagonia: la territorialidad en debate. Perspectivas ambientales, culturales, sociales, políticas y económicas, Bariloche, Iidypca-Conicet/unrn, (2013):

32-53.

Disponible

en

https://colegioturismo2013.files.wordpress.com/2013/05/trabajo-sobrejesuitas-de-parte-de-graciela-montero.pdf

Pastoriza, Elisa. La conquista de las vacaciones. Breve historia del turismo en la Argentina (1a. ed.). Buenos Aires: Edhasa, 2011.

- - - - y Torre, Juan Carlos. Mar del Plata. Un sueño de los argentinos (1. ${ }^{\mathrm{a}}$ ed.). Buenos Aires: Edhasa, 2019.

Piglia, Melina, «Turismo en automóvil en Argentina (1920-1950)». Tempo Social, 30 (2018): 87-111.

Raffa, Cecilia, «El avance del Estado: arquitectura y políticas públicas en el territorio (Mendoza-Argentina, 1932-1943)». Avances del cesor, 15 (2018a): 25-47. Disponible en conicet.gov.ar/ojs/index.php/AvancesCesor/index

https://web2.rosario-

- - - - «El turismo como estrategia del Estado: visiones políticas y aportes técnicos en Mendoza (1936-1943)». Anuario de la Escuela de Historia Virtual, 17 (2020b): 104-127.

Sautu, Ruth; Boniolo, Paula; Dalle, Pablo y Elbert, Rodolfo. Manual de metodología. Clacso, colección Campus Virtual, Buenos Aires, 2005. 
Trachana, Angelique. Historia y Proyecto. Una revisión de los conceptos de tipo y contexto. (1. ${ }^{\mathrm{a}}$ Ed.) Buenos Aires: Nobuko, 2011.

Van Dijk, Teun, «Estudios críticos del discurso: un enfoque sociocognitivo». Discurso y Sociedad, 10 (2016): 137-162. Disponible en: http://repositorio.ciem.ucr.ac.cr/handle/123456789/230

Waisman, Marina. El interior de la Historia. Historiografía Arquitectónica para uso de Latinoamericanos. Bogotá: Escala, 1993.

-_-_- La estructura histórica del entorno. Buenos Aires: Ediciones Nueva Visión saic, 1972.

Walton, John, «Aproximación a la historia del turismo en el Reino Unido, siglos xviiixx». Historia Contemporánea, 25 (2002): 65-82. 